\title{
Further thoughts on replacement demand in Europe. With a focus on ageing of the workforce
}

Citation for published version (APA):

Künn-Nelen, A. C. (2015). Further thoughts on replacement demand in Europe. With a focus on ageing of the workforce. ROA. ROA Technical Reports No. 001 https://doi.org/10.26481/umarot.2015001

Document status and date:

Published: 01/01/2015

DOI:

10.26481/umarot.2015001

Document Version:

Publisher's PDF, also known as Version of record

\section{Please check the document version of this publication:}

- A submitted manuscript is the version of the article upon submission and before peer-review. There can be important differences between the submitted version and the official published version of record.

People interested in the research are advised to contact the author for the final version of the publication, or visit the DOI to the publisher's website.

- The final author version and the galley proof are versions of the publication after peer review.

- The final published version features the final layout of the paper including the volume, issue and page numbers.

Link to publication

\footnotetext{
General rights rights.

- You may freely distribute the URL identifying the publication in the public portal. please follow below link for the End User Agreement:

www.umlib.nl/taverne-license

Take down policy

If you believe that this document breaches copyright please contact us at:

repository@maastrichtuniversity.nl

providing details and we will investigate your claim.
}

Copyright and moral rights for the publications made accessible in the public portal are retained by the authors and/or other copyright owners and it is a condition of accessing publications that users recognise and abide by the legal requirements associated with these

- Users may download and print one copy of any publication from the public portal for the purpose of private study or research.

- You may not further distribute the material or use it for any profit-making activity or commercial gain

If the publication is distributed under the terms of Article $25 \mathrm{fa}$ of the Dutch Copyright Act, indicated by the "Taverne" license above, 


\section{Further thoughts on replacement demand in Europe}

With a focus on the ageing of the workforce

Annemarie Künn-Nelen

\section{ROA Technical Report}

ROA-TR-2015/1

Researchcentrum voor Onderwijs en Arbeidsmarkt | ROA

Research Centre for Education and the Labour Market | ROA 


\section{Further thoughts on replacement demand in Europe}

With a focus on the ageing of the workforce

Annemarie Künn-Nelen

ROA-TR-2015/1

January 2015

Research Centre for Education and the Labour Market

Maastricht University

P.O. Box 616, 6200 MD Maastricht, The Netherlands

$\mathrm{T}+31433883647 \mathrm{~F}+31433884914$

secretary-roa-sbe@maastrichtuniversity.nl

www.roa.nl 


\section{Preface and Acknowledgements}

This report summarises some of the latest results from the Cedefop Skillsnet project on Forecasting skill supply and demand in Europe to 2022. This is part of an ongoing Framework Agreement which extends over 4 years. This report documents work carried out in Year 2 (2014). The researchers are grateful to Cedefop for financial support (the Framework Agreement relates to open invitation to tender No: AO/RPA/AZU-VKVET/skill-forecast/003/12).

The results are the outcome of a team effort. The authors are grateful to all of the team including the Country Group Experts for their contributions. In this context, I am especially grateful to colleagues of ESME (predicted participation rates) and AM (harmonized European labour force survey) who provided me the relevant data to estimate the replacement demand. Thanks are also due to the various experts from individual countries who have taken time to review and comment on the emerging findings.

Finally, thanks are due to Ineke Bijlsma, Didier Fouarge, Ben Kriechel, Vladimir Kvetan and Rob Wilson for sharing their ideas and thoughts on the issues raised in this report. 


\section{Contents}

Preface and Acknowledgements

Abstract

Summary

V

1 Introduction 1

2 Replacement demands in Europe 4

2.1 Model 4

2.2 Ageing of the workforce and implications for RD 6

3 Changes in expected participation rates for forecasted years 8

3.1 Increase in participation rates of elderly by $8 \%$-points over 10 years 8

3.2 Imposing the predicted Dutch increase in older workers' labour market participation on all countries

4 Delayed outflow due to retirement 12

4.1 The elderly in the labour market $\quad 12$

4.2 Extending retirement age 14

$\begin{array}{ll}4.3 \text { Decreasing outflow coefficients } & 15\end{array}$

5 How sensitive is the replacement demand with respect to changes in participation and outflow?

6 Discussion and conclusions $\quad 20$

7 References $\quad 21$

8 Appendix 22

8.1 Baseline scenario for Europe as a whole 22 


\section{Glossary}

AM - Alphametrics

CE - Cambridge Econometrics

CGEM - Computable General Equilibrium Modelling

CGEs - Country Group Experts

CM - Computable model

DTI - Danish Technological Institute

E3ME the multisectoral macroeconomic model underlying the projections

EPC - Education Policy Centre

ERC - Economix Research \& Consulting, Munich

FGB - Fondazione Giacomo Brodolini, Roma

ICEs - Individual Country Experts

IER - Institute for Employment Research

IHS - Institute for Advanced Studies, Vienna

MLME - the Melbourne (previously Monash) Labour Market Extension (CGE module

to extend the results from E3ME

NTF - National Training Foundation, Prague

ROA - Research Centre for Education and the Labour Market, Maastricht

VA - Visionary Analytics, Vilnius

VA - Value Added (projects)

WLME - the Warwick labour Market Extension - the various modules developed to extend the E3ME model to cover the demand for and supply of skills 


\section{Abstract}

This report presents an overview is given of sensitivity analyses of the replacement demand model (RDMOD) as part of the European skills forecasts. Three policyrelated scenarios are reported and compared to the baseline scenario. The first two scenarios imply changes in the expected participation rates for the forecasted years. The third scenario takes the predicted participation rates from E3ME as given and instead modifies the observed outflow rates. Here, we allow for heterogeneous reductions in outflow rates across occupational level. From the exercises we can conclude that changes in the predicted participation rates (for age-sex-year combinations) do not affect RD to a large extent. This might be due to the chosen scenarios, but the overall impression is that $\mathrm{RD}$ is quite robust with respect to slight changes in the predicted participation rates. Playing around with outflow coefficients affects the model to a much larger extent. 


\section{Summary}

This note presents an overview of sensitivity analyses of the replacement demand model (RDMOD) as part of the European skills forecasts. The reasons for this exercise are twofold. First, there is the need to better understand to what extent the ageing of the workforce and related policies to postpone the retirement decision have an impact on the replacement demand. Second, there is the need to incorporate some sensitivity analysis into the replacement demand in the workbooks of the European skills forecasts project so that users are able to assess the effect of various assumptions on the estimated replacement demand. Because the term replacement demand refers to a theoretical construct it is often difficult to have a concrete view of it. By modifying assumptions, the replacement demand should become more lively for a broader public.

In Wilson et al. (2013) it is shown that about half of the European RD can be attributed to retirement. Due to the ageing of the workforce, most European countries provide incentives to postpone workers' retirement decision. If these policies are successful, elderly workers will be working until a later age than they did in the last decade. Delaying retirement implies that the replacement demand will be lower, at least temporarily.

In general terms, replacement demand (RD) can be seen as job openings arising because of people leaving the workforce or their occupation (temporary). The main reasons for leaving the workforce are retirement, emigration, and especially for women family formation and taking care of children. Next to withdrawals from the labour force, the RD also includes movements of workers from one occupation to another. These movements leave a vacancy for the occupation left; hence demand for a worker to fill that vacancy.

The replacement demand is derived from a combination of the estimated outflow coefficients (based on historical outflow) per age-gender-occupation and the predicted change in participation rates per age-gender. The estimated net flow is entering the RD with a negative sign as a net outflow implies that more replacement is needed. The estimated net flow is corrected for the predicted change in participation rates; if labour market participation of elderly (both men and women) is expected to increase, the estimated net flow will be overestimated, so the RD needs to be revised downwards.

If policies targeting at delaying retirement decisions are successful, this will change both components of the RD. On the one hand, if the observed number of workers in the older age categories per gender and occupation increases over time because older workers work longer, this will result in lower net flow coefficients. On the other hand, the predicted participation rates for the projection years will increase as a consequence of promising policies. The scenario's we propose imply changes in either the net flow or the predicted participation rates. 
In this report, we provide three policy related scenarios. The first two scenarios imply changes in the expected participation rates for the forecasted years. The RDMOD makes use of the predicted participation rates from E3ME. For each forecasted year, E3ME provides expected participation rates per age category and gender. In the baseline scenario, these participation rates are included in the model to correct the past outflow behaviour of the workforce for expected changes in participation. In Scenario 1 , we assume the participation rates of the elderly to increase by $8 \%$ into the next 10 years (based on findings from Nelissen, 2001). This means an annual extra increase in the predicted participation of $0.8 \%$-points for the workers aged $55+$. This reflects the potential increase in labour market participation following the retrenchment of pension systems in Europe. In Scenario 2, we use the annual expected change in participation rates for older ages of the Netherlands and combine this with the base participation rate of the own country in the base year. The assumption here is that European countries engage in pension reforms that have similar effects on the labour market participation as those found in the Netherlands. We take the Netherlands as reference country as it is one of the country with most policies targeting at increasing labour market participation among the elderly (De Grip et al. 2013). The third scenario takes the predicted participation rates from E3ME as given and instead modifies the observed outflow rates. Within the model, outflow is calculated by the relative change between two years of the number of workers in a certain age-gender-occupation category. If policies are successful in postponing retirement, the outflow rates of elderly will decrease. As workers in lowskilled occupations in general retire earlier than workers in high-skilled occupations, and policies are more effective in postponing retirement of workers in high-skilled occupations, we lower the observed outflow rates in low-skilled occupations by $5 \%$ points and in high-skilled occupations by $10 \%$-points. This scenario therefore reflects the effect of a pension reform that has differential effects for different skill groups. All reported scenarios are expected to result in lower e replacement demand in the short to medium term (in the long-run everyone retires eventually!).

In this paper, we show the findings of these scenario's for two countries: Germany and Italy. We have chosen Germany as this county has similar participation rates than the Netherlands, the country for which we take the predicted increase in participation rates in one of the scenarios. Italy is included here as this country is among the countries with the lowest predicted participation rates of the elderly in 2020 (see Table 3.1).

All the different scenarios decrease the overall RD for Germany. Nevertheless, certain occupations exhibit an increase in the RD in some of the alternative scenarios. This holds especially for the scenarios in which we play around with the predicted participation rates. This is not surprising as Figure 3.1 in Künn-Nelen (2014) has shown that these scenarios do not always (i.e. not for all age, gender, year-combinations) increase the predicted participation rates compared to the baseline scenario. The extent to which RD is changed, therefore depends on the age-gender distribution of the occupations. 
The other two scenarios, by construction, imply a decrease in RD for all occupations. The overall RD is much more affected than in the other two alternative scenarios. The scenario in which the predicted outflow is decreased (with $5 \%$ for the low-skilled occupations and with $10 \%$ for the high-skilled occupations) decreases the overall RD to $2.21 \%$. It does not come as a surprise that the RD in the high-skilled occupations decreases more than in the low-skilled occupations. The scenario in which the retirement age is extended to 70 , also clearly leads to a reduction in the RD. On average it holds that the larger the percentage of the elderly, the larger the decrease in $\mathrm{RD}$ due to a later retirement age.

The baseline scenario in Italy yields a lower RD than in Germany, $2.71 \%$ of the workers in Italy need to be replaced on average each year. The scenario in which the 2010-participation rate is yearly increased by $0.8 \%$-points only implies a small decrease in the overall RD. As in the German case, not for all underlying occupations, the RD decreases. Nevertheless, for most of the low-skilled occupations, the RD does decrease slightly in this alternative scenario.

The scenario in which the changes in predicted participation rates for the Netherlands are put onto those for Italy pays off more than in the German case. This is not too surprising as for Italy, the expected participation rates under this scenario are for men clearly higher than in the baseline scenario (see Figure 3.2).

Adjusting outflow coefficients lowers the RD to an unrealistic level, the overall $R D$ is predicted to be $1.76 \%$ in this scenario. The scenario in which the constructed retirement age is set to be 70 , decreases the overall $\mathrm{RD}$ to $2.25 \%$. Again, the $\mathrm{RD}$ decreases most for occupations in which the percentage of the elderly is larger.

From these exercises we can conclude that changes in the predicted participation rates (for age-sex-year combinations) do not affect RD to a large extent. This might be due to the chosen scenarios, but the overall impression is that $R D$ is quite robust with respect to slight changes in the predicted participation rates. Playing around with outflow coefficients affects the model to a much larger extent. Whereas this scenario might look much more abstract than the scenario in which the predicted participation rates are changed, this is not necessarily the case. The scenario in which we play around with the outflow coefficients stands for the (maybe even more realistic case) in which policy changes heterogeneously stimulate workers to stay in the labour market for a longer time. The extent to which we lower outflow might be overdone, but the idea is that not all workers react to policies in the same way. In this case, we have distinguished between workers in low- and high-skilled occupations due to differences in occupational demands. 


\section{Introduction}

This report presents an overview is given of sensitivity analyses of the replacement demand model (RDMOD) as part of the European skills forecasts. ${ }^{1}$ The reasons for this exercise are twofold. First, there is the need to better understand to what extent the ageing of the workforce and related policies to postpone the retirement decision have an impact on the replacement demand. Second, there is the need to incorporate some sensitivity analysis into the replacement demand in the workbooks of the European skills forecasts project so that users are able to assess the effect of various assumptions on the estimated replacement demand. Because the term replacement demand refers to a theoretical construct it is often difficult to have a concrete view of it. By modifying assumptions, the replacement demand should become more lively for a broader public.

In general terms, replacement demand (RD) can be seen as job openings arising because of people leaving the workforce or their occupation (temporary). The main reasons for leaving the workforce are retirement, emigration, and especially for women family formation and taking care of children. Next to withdrawals from the labour force, RD also includes movements of workers from one occupation to another. These movements leave a vacancy for the occupation left; hence demand for a worker to fill that vacancy. ${ }^{2}$

In Wilson et al. (2013) it is shown that about half of the European RD can be attributed to retirement. Due to the ageing of the workforce, most European countries provide incentives to postpone workers' retirement decision. If these policies are successful, elderly workers ${ }^{3}$ will be working until a later age than they did in the last decade. Delaying retirement implies that the replacement demand will be lower, at temporarily.

In Wilson et al. (2013), first sensitivity analyses are reported with respect to the ageing of the workforce. In that report, the replacement demand was estimated according to three scenarios. In the first, basic scenario, we assume all workers to retire at the age of $67.5 .{ }^{4}$ In the scenario "low", all workers retire a bit earlier, at the age of 65 . In the scenario "high", all workers retire from the age of 70 onwards. ${ }^{5}$ By construction, increasing the retirement age decreases replacement demand in the short-term. Over all European countries, the observed decrease was most prolonged for teaching professionals. Instead of a yearly replacement demand of $3.4 \%$, a

1. The results are reported in the ISCO-88 classification as the replacement demand is still estimated at the ISCO-88 level due to a lack of historical data in ISCO-08 which is needed for the estimation of the European replacement demand.

2. For a detailed description of the RD model, see Wilson et al. (2013) Mid-term skills supply and demand forecast. Methodology and Assumptions. Deliverable \#2 (in response to open invitation to tender Cedefop No:AO/RPA/AZU-VKVET/skill-forecast/003/12).

3. Elderly workers are defined as workers aged $55+$

4. This is the scenario which is also reported in Kriechel (2011).

5. ROA (2011) has performed similar robustness analyses for the Dutch replacement demand forecasts. 
replacement demand of $2.7 \%$ is predicted if the retirement age would be increased by 2.5 years (to 70 ). This implies that within this occupation, the average age is relatively high. This holds also for the other occupations that observed a relatively large decrease in the predicted replacement demand. ${ }^{6}$

In this report, we provide three additional policy related scenario's. The first two scenario's imply changes in the expected participation rates for the forecasted years. The RDMOD makes use of the predicted participation rates from E3ME. For each forecasted year, E3ME provides expected participation rates per age category and gender. In the baseline scenario, these participation rates are included in the model to correct the past outflow behaviour of the workforce for expected changes in participation. In Scenario 1, we assume the participation rates of the elderly to increase by $8 \%$ into the next 10 years (based on findings from Nelissen, 2001). This means an annual increase in the predicted participation of $0.8 \%$-points for the workers aged 55+ compared to the participation in the base year. This reflects the potential increase in labour market participation following the retrenchment of pension systems in Europe. In Scenario 2, we use the annual expected change in participation rates for older ages of the Netherlands and combine this with the base participation rate of the own country in the base year. The assumption here is that European countries engage in pension reforms that have similar effects on the labour market participation as those found in the Netherlands. We take the Netherlands as reference country as it is one of the country with most policies targeting at increasing labour market participation among the elderly (De Grip et al. 2013). The third scenario takes the predicted participation rates from E3ME as given and instead modifies the observed outflow rates. Within the model, outflow is calculated by the relative change between two years of the number of workers in a certain age-genderoccupation category. ${ }^{7}$ If policies are successful in postponing retirement, the outflow rates of elderly will decrease. As workers in low-skilled occupations in general retire earlier than workers in high-skilled occupations, and policies are more effective in postponing retirement of workers in high-skilled occupations, we lower the observed outflow rates in low-skilled occupations by $5 \%$-points and in high-skilled occupations by $10 \%$-points. This scenario therefore reflects the effect of a pension reform that has differential effects for different skill groups. All reported scenarios are expected to result in lower replacement demand in the short to medium term (in the long-run everyone retires eventually).

In this report, we show the findings of these scenario's for two countries: Germany and Italy. We have chosen Germany as this county has similar participation rates than the Netherlands, the country for which we take the predicted increase in participation rates in one of the scenarios. Italy is included here as this country is among the countries with the lowest predicted participation rates of the elderly in 2020 (see Table 3.1).

6. Detailed results of these analyses for the two countries under scrutiny, Germany and Italy, can be found in the Appendix.

7. The precise way of estimating the outflow is slightly more complicated but this is the basically the idea. 
From the exercises we can conclude that changes in the predicted participation rates (for age-sex-year combinations) do not affect RD to a large extent. This might be due to the chosen scenarios, but the overall impression is that RD is quite robust with respect to slight changes in the predicted participation rates. Playing around with outflow coefficients affects the model to a much larger extent.

The outline of this report is as follows. Section 2 briefly discusses the RDMOD and the implications of the ageing of the workforce for RD. Section 3 describes the two scenario's in which the participation rates of E3ME are adjusted. In Section 4 the third scenario is described in which we adjust the outflow coefficients of workers in high versus low-skilled occupations. Section 5 shows how sensitive the RDMOD is with respect to the underlying assumptions and the observed outflow (based on current policies). Section 6 concludes. 


\section{Replacement demands in Europe}

\subsection{Model}

The methodology for calculating the replacement demand follows the approach used by the Research Centre for Education and the Labour Market (ROA) in its national forecasts (Clerx et al. 2014), adapted for the data availability of the other European countries. ${ }^{8}$ It is based on the cohort-component analysis that uses the EU-LFS for all countries, while disaggregating education into several ISCED categories (for replacement demand by education) and ISCO categories (allowing estimates of replacement demand by occupation).

There are three components to the model:

a) a forecast of demographic development within a country;

b) a forecast of (changes in) participation, preferably by gender and age groups:

c) an estimate of the outflow by occupation (education) category, gender and age group.

Components (a) and (b) are usually considered external to the replacement demand model. Current estimations are based on the baseline model of the most current Europop forecast, which was the most recent demographic forecast by Eurostat. Changes in labour market participation use the participation rate by country, age and gender as generated within the E3ME model. This insures consistency across the entire set of forecasts.

The basic steps use occupation (subindex o) as the relevant subcategory. However, one can interpret the methodology analogously if education is used instead. For the purposes of the Cedefop forecast, education is not estimated separately given the high level of aggregation on the education variable. Rather, the replacement demand by education is deduced from the occupational replacement demand. By using the occupational replacement demand and imposing the most recent distribution of education by occupation, we are able to present the most likely replacement demand using the current demand for education levels within an occupational class.

Table 1 gives a schematic input-output table of the labour force/population in a country (see also Willems and de Grip, 1993). The first rectangle gives the movements within the labour market. The second, bigger rectangle encompasses movements out of the labour market, while the third rectangle also considers changes in the population. Adding rows (for time t) or columns (for time $t-n$ ) of these flows gives the total population within an occupation.

8. A large part of this chapter is based on Kriechel (2011). 
Table 2.1 Schematic overview of replacement demand

\begin{tabular}{|l|l|l|l|l|l|l|}
\hline Outflows & $\begin{array}{l}\text { Occupation } \\
\mathbf{1}\end{array}$ & $\begin{array}{l}\text { Occupation } \\
\mathbf{2}\end{array}$ & $\begin{array}{l}\text { Unemployed } \\
\text { Inflows }\end{array}$ & $\begin{array}{l}\text { Outside } \\
\text { the } \\
\text { labour } \\
\text { force }\end{array}$ & $\begin{array}{l}\text { Outflow } \\
\text { populations }\end{array}$ & Total \\
\hline Occupation 1 & $\mathrm{A}$ & $\mathrm{B}$ & $\mathrm{C}$ & $\mathrm{D}$ & & $\mathrm{W} 1, \mathrm{t}-\mathrm{n}$ \\
\hline Occupation 2 & $\mathrm{E}$ & & & & & $\mathrm{W} 1, \mathrm{t}-\mathrm{n}$ \\
\hline Unemployed & $\mathrm{F}$ & & & & & \\
\hline $\begin{array}{l}\text { Outside the } \\
\text { labour force }\end{array}$ & $\mathrm{G}$ & & & & & \\
\hline $\begin{array}{l}\text { Inflow } \\
\text { population }\end{array}$ & & & & & & \\
\hline Total & $\mathrm{W} 1, \mathrm{t}$ & $\mathrm{W} 1, \mathrm{t}$ & & & & \\
\hline
\end{tabular}

Source: Willems and De Grip (1993)

Several flows are indicated in the table with capital letters. $A$ denotes the workers who work in occupation 1 at time t-n and continue to do so in period $t$. $B$ denote the workers who move from occupation 1 to occupation 2 in the observed time. $E$ denotes the opposite movement from 2 to 1 . Thus, $B$ and $E$ denote the job-to-job mobility. $C$ and $D$ denote movements out of the labour market from individuals in occupation 1. Corresponding inflows into occupation 1 are $F$ and $G$ in the table.

The first step in modelling future replacement demand per occupational class is a description of the inflow and outflow patterns by occupational class in a historical period. Because there are no appropriate data for mobility flows on the labour market, stock data are used. With the cohort components method, cohort-change rates based on the number of persons of the same birth cohort who were employed at two different time periods can be calculated (Shryock and Siegel, 1980). These cohort-change rates can be rewritten as average annual net inflow or outflow percentages (flow rates for males and females are differentiated):

$\dot{F}_{o, a}^{t-1}=\frac{k \boldsymbol{W}_{o, a+1}^{t}-k \boldsymbol{W}_{O, a}^{t-1}}{k \boldsymbol{W}_{o-a}^{t-1}}$

Where $\dot{F}_{o, a}^{t-1}$ is the annual net inflow or outflow ratio of workers in occupational class 0 of age group a (with class width $k$ ) at time $t$ - 1 during the period $(t-1, t) ; \boldsymbol{W}_{o, a}^{t}$ is the number of people working in occupational class $o$ of age group a (with class width $k$ ) at time $t$. The time lags are used to describe how particular cohort is moving within an occupation. If $\dot{F}_{o, a}^{t-1}>0$, there is a net inflow for a certain age group from an occupational class, and if $\dot{F}_{o, a}^{t-1}<0$ there is a net outflow.

The second step in modelling is to translate these inflow- and outflow-percentages into the replacement demand by occupational class. For occupational classes with an increase in employment in the period $(t-1, t)$, replacement demand is equal to total net outflow in this period. However, for occupational classes which faced a decrease in employment, not all vacancies created by the outflow of workers will have been filled 
by new workers. Therefore, replacement demand for these occupational classes equals the number of vacancies likely to be actually refilled, that is to say the total inflow of workers into the occupational class. In this way, the more or less 'structural' replacement demand is derived. This methodology measures only the net flow to or from an occupational class. This means that replacement demand satisfied by reentering workers of the same age cohort is not measured. So replacement demand is actually measured only for newcomers to the labour market.

A model is then estimated in which the net inflow or outflow ratios are explained on the basis of the average inflow or outflow from the total working population on the one hand, and the occupation-specific deviations per age-gender group on the other. This approach guarantees that the sum of the net flows among the occupations corresponds to the total inflow or outflow.

Written mathematically:

$\dot{F}_{o}=\dot{F}+\sum_{k} \beta_{o k} D_{x}$

Where: $\dot{F}_{o}$ is the vector of net inflow of outflow ratios for occupation 0 , with observations for gender, age group and year; $\dot{F}$ is the vector of net inflow - outflow ratios for the total working population; $D_{x}$ is the matrix with dummy variables where elements are equal to 1 for cohort $x$ and 0 elsewhere; $\beta_{o k}$ and represents random parameters.

The third step is to project the historically measured net replacement demand rates per age-gender group for a particular occupational class onto the age-gender structure of the workers at the beginning of the forecasting period. The outflow coefficient is then combined with changes in the participation rates and applied to the population of workers within an age cohort. An increase in participation rates implies less replacement demand. Higher participation rates of workers manifest themselves in this model by lower outflow rates. Given that we estimate on historic outflow rates, the estimated coefficient of outflow will be too high for the future. The expected increase in the participation rate is included by correcting the outflow coefficient for these changes in participation rate.

Finally, a projection is made based on the estimated coefficient combined with participation rate changes applied to the age-gender structure of the occupation as predicted by demographic and participation forecasts. To model the demographic composition of an occupation and its dynamic changes, we project uniform changes of one age cohort in the next cohort over the full time-horizon of the forecasts.

\subsection{Ageing of the workforce and implications for RD}

The replacement demand is derived from a combination of the estimated outflow coefficients (based on historical outflow) per age-gender-occupation and the 
predicted change in participation rates per age-gender. In a simplified manner, RD is calculated as follows:

$R D_{x, g, o}=-N E T F L O W_{x, g, o}-P A R T_{x, g}$

The estimated net flow is entering RD with a negative sign as a net outflow implies that more replacement is needed. The estimated net flow is corrected for the predicted change in participation rates; if labour market participation of elderly (both men and women) is expected to increase, the estimated net flow will be overestimated, so RD needs to be revised downwards.

If policies targeting at delaying retirement decisions are successful, this will change both components of RD. On the one hand, if the observed number of workers in the older age categories per gender and occupation increases over time because older workers work longer, this will result in lower net flow coefficients. On the other hand, the predicted participation rates for the projection years will increase as a consequence of promising policies.

It is therefore, that the scenario's we propose imply changes in the net flow or the predicted participation rates. 


\section{Changes in expected participation rates for forecasted years}

Table 3.1 reports the forecasted participation rates in 2020 in European countries for 55-60 and 61-65 year old men and women. We observe large differences across the European countries. We observe a few countries in which it is expected that at least 9 out of 10 male workers in the age category 55-60 are working in $2020(\mathrm{CH}, \mathrm{CZ}, \mathrm{DK}$, IS, SE). However, in four countries less than 7 out of 10 male workers are expected to still be active in the labour market (IT, LU, SI, TR). Also with respect to the participation of women in 2020 there is much heterogeneity across European countries. In TR and MT less than one third of the women aged 55-60 are expected to work in 2020. In all countries we find that for both men and women the probability of working decreases tremendously after age 60 .

The table also shows the change, most often the increase, between participation rates in 2010 and in 2020 . For most countries, the participation rates are expected to increase. There is a lot heterogeneity in the expected increase in participation. In Hungary participation of $55-60$ years old is expected to increase more than $15 \%$ points. For the 61-65 years old, there is almost no increase expected in participation. In SI the participation of this oldest group of workers is even expected to decline. This also holds for CY, GR and PT. In BG, FR, HU, LV, PL, NO and NL the prediction is that participation rates are rising quite a bit.

\subsection{Increase in participation rates of elderly by $\mathbf{8 \% - p o i n t s ~ o v e r ~} \mathbf{1 0}$ years}

In this section, we will describe Scenario 1 in which we increase the participation rates of each country for elderly men and women by $8 \%$-points. Nelissen (2001) found that the introduction of flexible retirement systems could increase labour market participation by $8 \%$ (over 10 years). Therefore, in Scenario 1, we test the sensitivity of our model when increasing the expected participation rates of elderly men and women by $8 \%$ over 10 years, i.e. by $0.8 \%$-points each year as of the base year in 2010 .

\subsection{Imposing the predicted Dutch increase in older workers' labour market participation on all countries}

In the Netherlands, early retirement schemes have been abolished and the mandatory retirement age is gradually shifted upwards (Fouarge \& De Grip 2014). The retrenchment of early pension schemes has resulted in an increase of older workers' labour market participation (Euwals et al. 2010). It is expected that the increase in the mandatory pension age will increase this participation rate even further (De Grip et al. 2013). We take the Netherlands as the example country in which policies aimed at increasing participation of older workers have been quite successful in the recent past (OECD 2014). ${ }^{9}$

9. For an overview of all Dutch pension reforms since the 1990s, see De Grip et al. (2013). 
Table 3.1 Predicted participation rates and changes for elderly men and women

\begin{tabular}{|c|c|c|c|c|c|c|c|c|}
\hline \multirow{3}{*}{ country } & \multicolumn{4}{|c|}{ Men } & \multicolumn{4}{|c|}{ Women } \\
\hline & \multicolumn{2}{|r|}{$55-60$} & \multicolumn{2}{|c|}{$61-65$} & \multicolumn{2}{|c|}{$55-60$} & \multicolumn{2}{|c|}{$61-65$} \\
\hline & 2020 & $2020-2010$ & 2020 & $2020-2010$ & 2020 & $2020-2010$ & 2020 & $2020-2010$ \\
\hline AT & $81 \%$ & $8 \%$ & $32 \%$ & $1 \%$ & $54 \%$ & $1 \%$ & $16 \%$ & $1 \%$ \\
\hline$B E$ & $70 \%$ & $4 \%$ & $30 \%$ & $2 \%$ & $52 \%$ & $6 \%$ & $19 \%$ & $4 \%$ \\
\hline$B G$ & $75 \%$ & $14 \%$ & $46 \%$ & $5 \%$ & $81 \%$ & $22 \%$ & $24 \%$ & $6 \%$ \\
\hline $\mathrm{CH}$ & $92 \%$ & $2 \%$ & $71 \%$ & $1 \%$ & $81 \%$ & $6 \%$ & $50 \%$ & $4 \%$ \\
\hline CY & $85 \%$ & $-3 \%$ & $58 \%$ & $-5 \%$ & $61 \%$ & $2 \%$ & $25 \%$ & $-5 \%$ \\
\hline$C Z$ & $92 \%$ & $7 \%$ & $48 \%$ & $9 \%$ & $70 \%$ & $10 \%$ & $19 \%$ & $3 \%$ \\
\hline DE & $88 \%$ & $3 \%$ & $64 \%$ & $8 \%$ & $80 \%$ & $9 \%$ & $43 \%$ & $6 \%$ \\
\hline DK & $90 \%$ & $3 \%$ & $56 \%$ & $6 \%$ & $84 \%$ & $4 \%$ & $37 \%$ & $4 \%$ \\
\hline EE & $78 \%$ & $3 \%$ & $53 \%$ & $1 \%$ & $82 \%$ & $2 \%$ & $50 \%$ & $4 \%$ \\
\hline ES & $81 \%$ & $1 \%$ & $48 \%$ & $1 \%$ & $66 \%$ & $17 \%$ & $32 \%$ & $5 \%$ \\
\hline $\mathrm{FI}$ & $76 \%$ & & $51 \%$ & $5 \%$ & $86 \%$ & $7 \%$ & $54 \%$ & $12 \%$ \\
\hline FR & $79 \%$ & $13 \%$ & $29 \%$ & $9 \%$ & $73 \%$ & $13 \%$ & $26 \%$ & $8 \%$ \\
\hline GR & $70 \%$ & $-2 \%$ & $39 \%$ & $-5 \%$ & $43 \%$ & $4 \%$ & $19 \%$ & $-3 \%$ \\
\hline HR & $72 \%$ & $-2 \%$ & $50 \%$ & $4 \%$ & $52 \%$ & $9 \%$ & $24 \%$ & $-2 \%$ \\
\hline $\mathrm{HU}$ & $79 \%$ & $16 \%$ & $18 \%$ & $0 \%$ & $68 \%$ & $17 \%$ & $13 \%$ & $3 \%$ \\
\hline IE & $72 \%$ & $-2 \%$ & $56 \%$ & $0 \%$ & $58 \%$ & $3 \%$ & $37 \%$ & $3 \%$ \\
\hline IS & $92 \%$ & $2 \%$ & $84 \%$ & $-2 \%$ & $84 \%$ & $-2 \%$ & $77 \%$ & $4 \%$ \\
\hline IT & $68 \%$ & $-1 \%$ & $33 \%$ & $2 \%$ & $51 \%$ & $9 \%$ & $17 \%$ & $4 \%$ \\
\hline LT & $81 \%$ & $5 \%$ & $56 \%$ & $10 \%$ & $81 \%$ & $9 \%$ & $40 \%$ & $10 \%$ \\
\hline LU & $66 \%$ & $0 \%$ & $26 \%$ & $1 \%$ & $61 \%$ & $16 \%$ & $24 \%$ & $10 \%$ \\
\hline LV & $87 \%$ & $10 \%$ & $47 \%$ & $10 \%$ & $86 \%$ & $8 \%$ & $40 \%$ & $9 \%$ \\
\hline MK & $82 \%$ & $4 \%$ & $49 \%$ & $2 \%$ & $44 \%$ & $4 \%$ & $23 \%$ & $5 \%$ \\
\hline MT & $80 \%$ & $4 \%$ & $31 \%$ & $5 \%$ & $28 \%$ & $7 \%$ & $0 \%$ & \\
\hline NL & $88 \%$ & $3 \%$ & $57 \%$ & $7 \%$ & $65 \%$ & $4 \%$ & $39 \%$ & $11 \%$ \\
\hline NO & $88 \%$ & $5 \%$ & $72 \%$ & $8 \%$ & $83 \%$ & $6 \%$ & $74 \%$ & $18 \%$ \\
\hline PL & $77 \%$ & $13 \%$ & $38 \%$ & $8 \%$ & $48 \%$ & $12 \%$ & $17 \%$ & $3 \%$ \\
\hline PT & $73 \%$ & $1 \%$ & $50 \%$ & $-1 \%$ & $58 \%$ & $3 \%$ & $32 \%$ & $-7 \%$ \\
\hline RO & $70 \%$ & $5 \%$ & $45 \%$ & $7 \%$ & $46 \%$ & $4 \%$ & $27 \%$ & $3 \%$ \\
\hline SE & $90 \%$ & $2 \%$ & $69 \%$ & $-2 \%$ & $84 \%$ & $2 \%$ & $63 \%$ & $4 \%$ \\
\hline SI & $68 \%$ & $4 \%$ & $24 \%$ & $-4 \%$ & $48 \%$ & $12 \%$ & $11 \%$ & $-3 \%$ \\
\hline SK & $85 \%$ & $4 \%$ & $37 \%$ & $8 \%$ & $69 \%$ & $19 \%$ & $12 \%$ & $4 \%$ \\
\hline TR & $51 \%$ & $-1 \%$ & $45 \%$ & $6 \%$ & $20 \%$ & $1 \%$ & $17 \%$ & $2 \%$ \\
\hline UK & $82 \%$ & $2 \%$ & $52 \%$ & $-5 \%$ & $68 \%$ & $1 \%$ & $36 \%$ & $1 \%$ \\
\hline
\end{tabular}

Source: E3ME 
Assuming that other countries in the EU take similar policies to increase the labour market participation rates of older workers that are equally successful as the Dutch policies, in this scenario we impose the forecasted increase in labour market participation of men and women aged 55 or older for the Netherland to the base participation rates of the relevant country in 2010 . We test what this would mean for the countries' replacement demand. ${ }^{10}$

The predicted participation rates from E3ME for the Netherlands (2010-2020) are reported in Table 3.2. From this table, we calculate the predicted annual increase in participation rates for the older workers (aged 55+) for both genders. These predicted annual increases in participation rates of Dutch elderly will be add onto the baseline participation rate of each country. For the other age categories, the predicted participation rates from E3ME are used (as in the default model).

Table 3.2 Predicted participation rates from E3ME for the Netherlands (20102020)

\begin{tabular}{|c|c|c|c|c|c|c|c|c|c|c|c|c|c|}
\hline age & sex & & 2010 & 2011 & 2012 & 2013 & 2014 & 2015 & 2016 & 2017 & 2018 & 2019 & 2020 \\
\hline \multirow[t]{2}{*}{$55-59$} & male & & 84.3 & 85.2 & 86.0 & 86.3 & 86.0 & 85.8 & 85.7 & 86.4 & 86.8 & 87.2 & 87. \\
\hline & female & & 61.0 & 64.5 & 65.7 & 65.0 & 64.9 & 64.9 & 64.9 & 65.0 & 64.9 & 64.8 & 64 \\
\hline $60-64$ & male & & 50.0 & 50.1 & 54.9 & 55.3 & 55.3 & 55.2 & 55.2 & 55.7 & 56.1 & 56.6 & 57 \\
\hline & ale & 8.1 & 31.4 & 35.6 & 36.0 & 36 & & & & 37.4 & 37.9 & 38.3 & 38.8 \\
\hline
\end{tabular}

Source: E3ME

In Figures 3.1 en 3.2 the baseline participation rates as predicted by E3ME as well as the alternative participation rates as described above are shown for elderly men and women. Figure 3.1 shows that the default participation rates in Germany are higher than in the alternative ones, except for men aged 55-59 (the largest group among the elderly). Figure 3.2 shows also for Italy that the default participation rates for women are higher than the alternative ones. For men, the picture looks different. Especially for men aged 60-64, the Dutch scenario would imply much larger participation rates than in the baseline scenario. For men aged 55-59, the alternative scenario's result in higher participation rates as of 2015.

10. The assumption here is that the policy changes would have the same effect on the labour market participation of other European countries, despite a different institutional context and baseline of participation rates among elderly. 
Figure 3.1 Baseline and alternative participation rates Germany
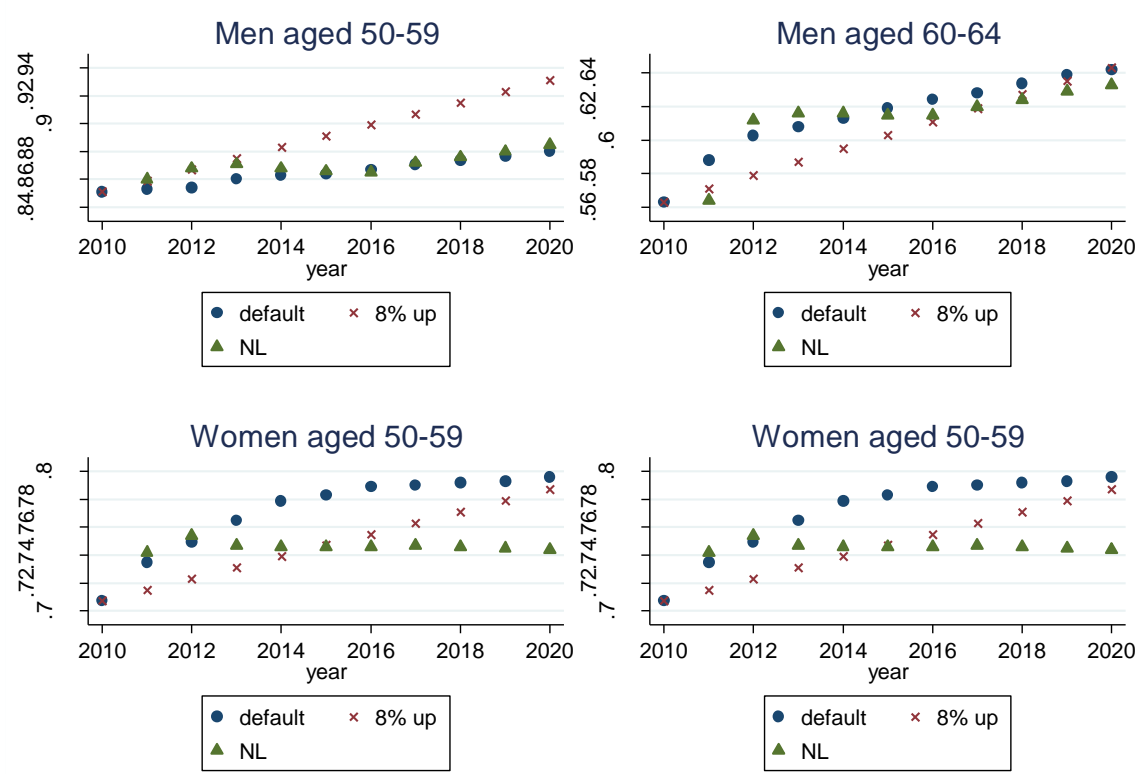

Women aged 50-59

Source: E3ME and ROA calculations

Figure 3.2 Baseline and alternative participation rates Italy
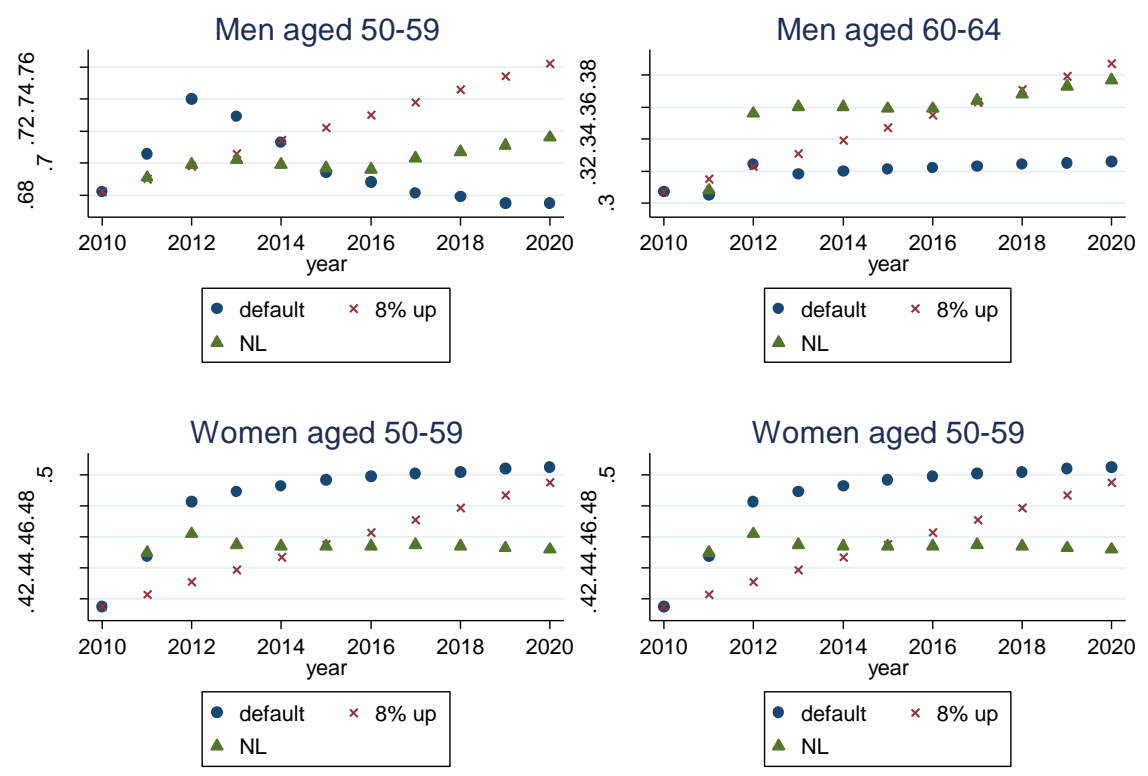

Source: E3ME and ROA calculations 


\section{Delayed outflow due to retirement}

\subsection{The elderly in the labour market}

In Europe, the workforce is greying: the percentage elderly is increasing and at the same time, the percentage of young workers is decreasing. As a consequence, policies try to stimulate workers to postpone their retirement decision. If these policies are successful, elderly workers who would have retired early in the past, will exit the labour market at a later stage. This implies that they have to be replaced later. As a consequence, the replacement demand will fall (and increase later when these elderly finally do retire).

In Figure 4.1 the observed age distribution of German workers is shown for all educational groups together and per ISCED code. From the overall picture, it can be seen that the workforce is quite old. Most workers are in age groups 6-9, implying an age between 40 and 59. This holds especially for men, but also for women. The number of workers aged between 15 and 19 is for both genders relatively small.

Figure 4.1 Age pyramid Germany
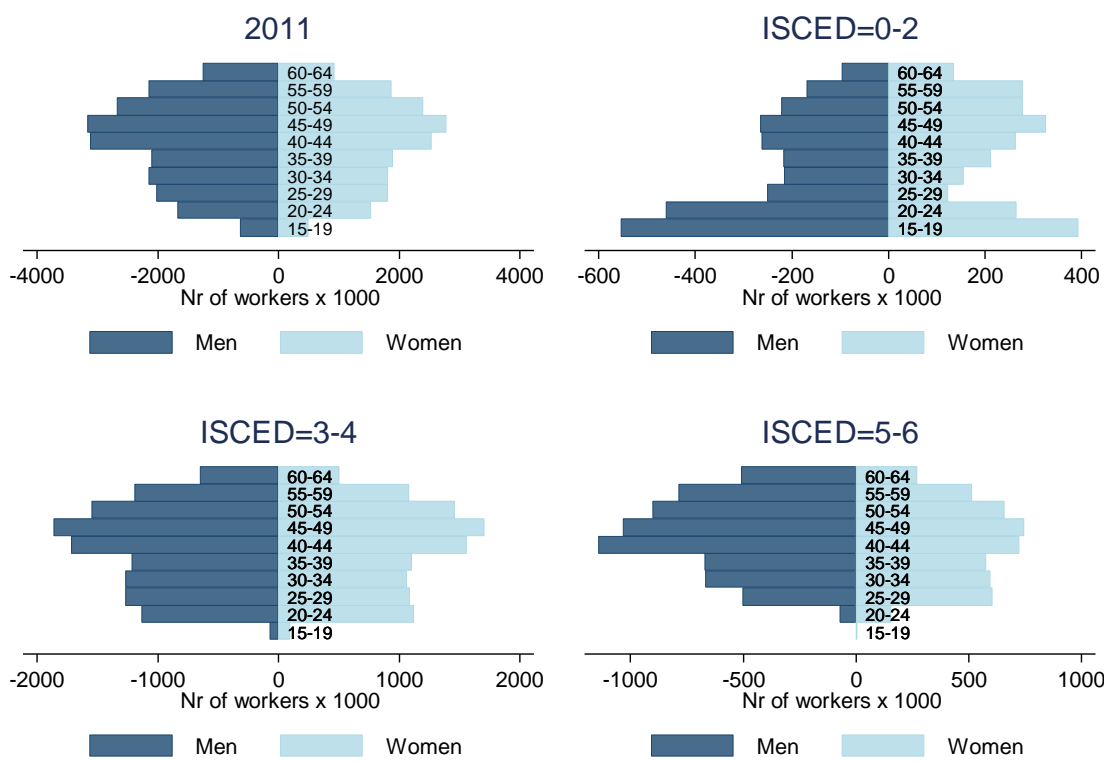

Source: LFS (calculated by ROA)

Whereas the age pyramid over all German workers seems to be normally distributed to some extent, this is not the case at all for the low-educated workers (isced=0-2). The largest group of workers is only 15-19 years old, and the number of workers decreases with age. For the medium-educated (isced=3-4) workers, the age pyramid looks similar to the overall one, though the number of workers aged 15-19 is relatively smaller among the medium-educated workers. The age distribution of the 
highly-educated (isced=5-6) workers is more concentrated on the older ages. There are almost no workers aged 15-19 years old. The fraction of workers below 40 is relatively small compared to the medium- and low-educated workers.

As described in Section 2, the replacement demand is to a large extent dependent on the outflow coefficients per age-gender-occupational groups. Therefore, Figures 4.2 -4.4 show the observed outflow rates. ${ }^{11,12}$

In Figure 4.2, the outflow of elderly workers since 2000 is shown. We distinguish between workers aged 55-59 and 60-64. We see that the outflow of elderly workers (both age groups) has decreased over the time. This means that in 2009 the percentage elderly that still works is higher than a decade ago. For the replacement demand this will imply, all else equal, a reduction/delay of replacement demand.

\section{Figure 4.2 Percentage net outflow of elderly workers in Germany}

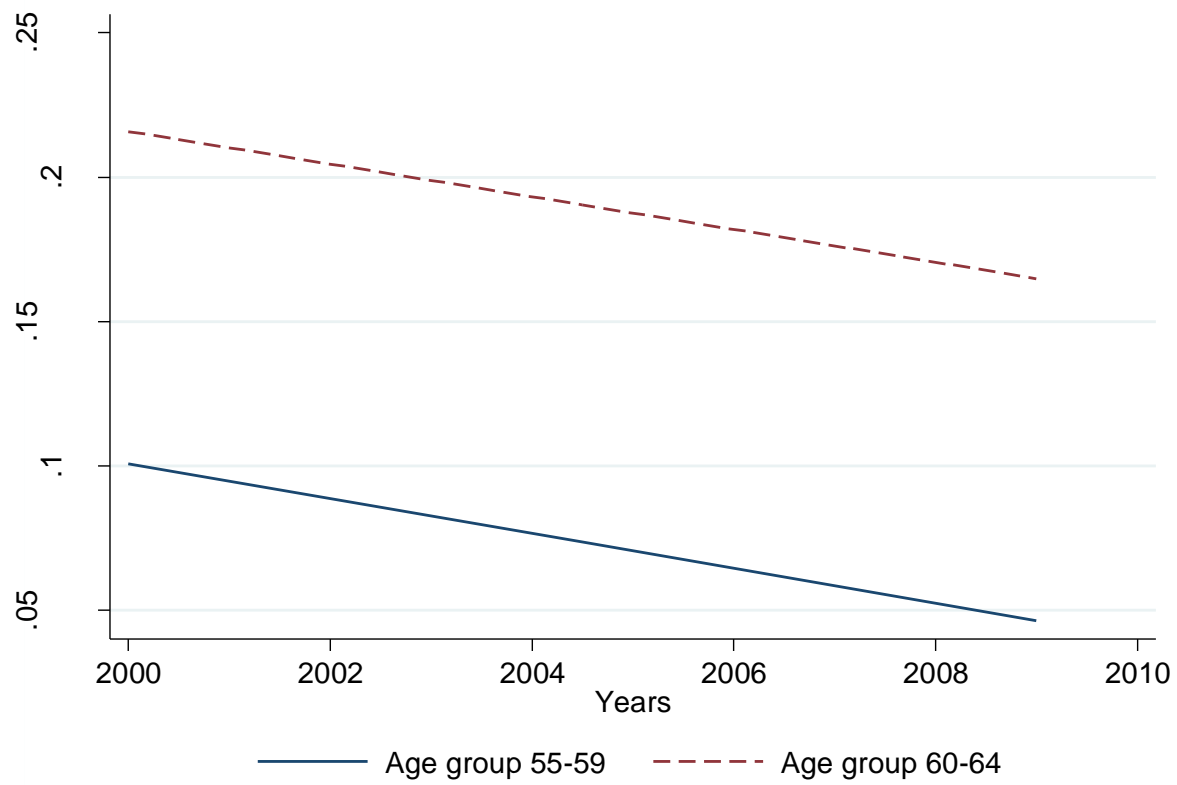

Source: RDMOD, calculated by ROA (based on LFS data)

Note: These lines are based on a fitted regression model to leave out annual fluctuations due to for example economic fluctuations.

In Figure 4.3 the outflow rates (from 2009 to 2010) for elderly workers (55+) are reported per isco-88 code. As can be seen from the figure, there is no clear

11. In the model, not the observed but estimated outflow rates are included. These estimated outflow rates are controlled for country-specific outflow rates, age-, gender-, and occupational structures of the country and estimated over 10 years.

12. Outflow consists not only of outflow due to retirement, but also for other reasons for exiting the labour market and outflow due to occupational mobility. 
observation that the outflow of older workers in low-skilled occupations (first digit isco-88 code: $4-9$ ) is higher than in high-skilled occupations (first digit isco-88 code: $1-3)$. The net outflow of elderly workers is highest among clerks and skill agriculture and fishery workers. For the elementary occupations, we even observe a small net inflow.

Figure 4.3 Percentage net outflow of elderly German workers per isco-88 code (2009)

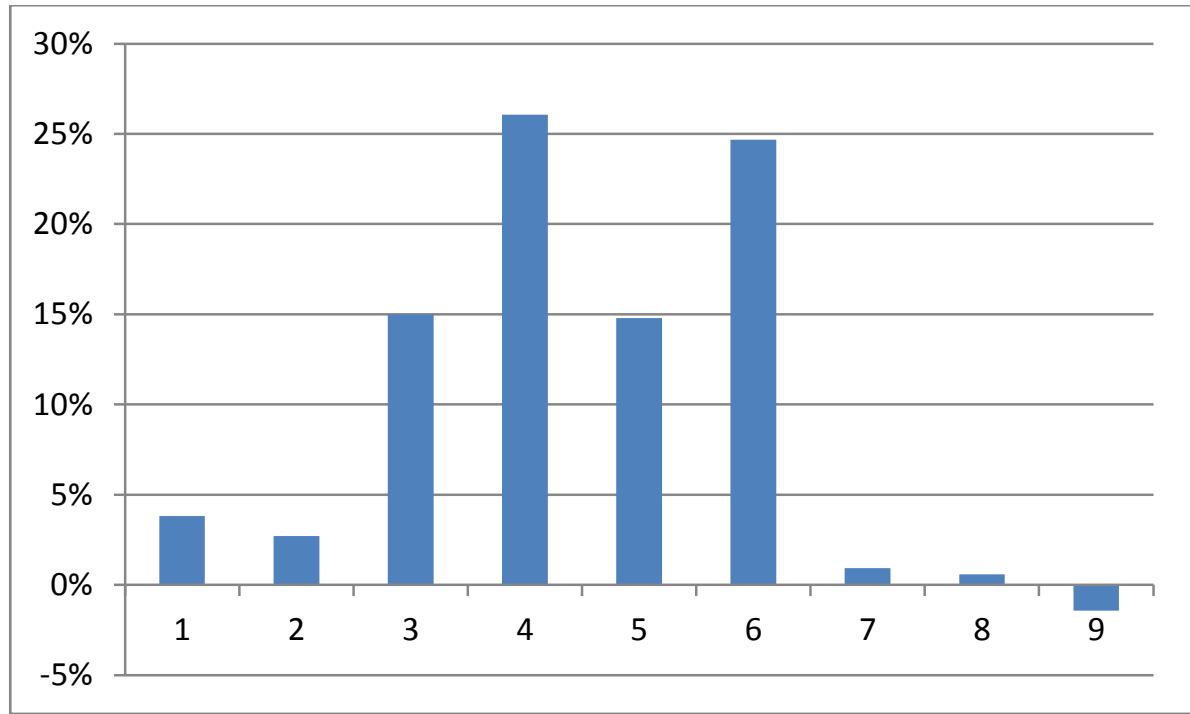

Source: RDMOD, calculated by ROA (based on LFS data)

\subsection{Extending retirement age}

To test the sensitivity of the results with respect to the retirement age, we have estimated the replacement demand based on three scenarios (Wilson et al. 2013). Within the basic scenario, we force all workers to retire at the age of 67.5 . In the scenario "low", all workers retire a bit earlier, at the age of 65. In the scenario "high", all workers retire from the age of 70 onwards.

Whereas the mandatory retirement age is not an exogenous variable in the current model, it is part of the model in a more indirect way. If the mandatory retirement age were extended to (say) 70, this would imply that not all workers from the age of 58 in the base year would leave the active labour force. Instead, a proportion of them will still be in work ten years later. In other words, the outflows for the older age-groups will be lower due to an increase in the obligatory retirement age, and therefore, the expected replacement demand will be lower.

In Wilson et al. (2013), results for all countries together are reported. Whereas the yearly replacement demand percentage averaged over all countries was $2.8 \%$ in the basic scenario, extending the age at which workers are forced to retire, results in a yearly replacement demand percentage of $2.3 \%$. On the contrary, the "low" scenario 
in which workers retire earlier, the replacement demand percentage is $3.5 \%$, which is $0.7 \%$-points higher than in the basic scenario. The degree to which the replacement demand changes due to a change in the retirement age, depends on the percentage of elderly within the active labour force.

\subsection{Decreasing outflow coefficients}

The model as it is now, is based on outflow per occupation, so to the extent that there are differences across occupations/educational levels, the model already incorporates this when predicting replacement demands.

Nevertheless, as literature suggests that policies targeting at postponing retirement age might be more successful for high-educated workers than for low-educated workers, we have estimated a scenario in which we lower the observed outflow coefficients by $10 \%$ for workers in the high-skilled occupations and by $5 \%$ for workers in the low-skilled occupations. 


\section{How sensitive is the replacement demand with respect to changes in participation and outflow?}

In this section, the results for two example countries are reported: Germany and Italy.

Table 5.1 Replacement demand Germany under baseline and alternative scenarios

\begin{tabular}{|c|c|c|c|c|c|c|}
\hline \multirow[t]{2}{*}{ isco } & \multirow[t]{2}{*}{ Default } & \multicolumn{2}{|c|}{ Changes in participation } & \multirow{2}{*}{$\begin{array}{l}\text { Adjusted } \\
\text { outflow }\end{array}$} & \multirow[t]{2}{*}{ Ret age } & \multirow[t]{2}{*}{$\%$ elderly } \\
\hline & & $8 \%$ up & NL & & & \\
\hline 1 & $1.05 \%$ & $1.07 \%$ & $1.05 \%$ & $0.08 \%$ & $1.02 \%$ & $0.77 \%$ \\
\hline 11 & $4.09 \%$ & $4.19 \%$ & $4.09 \%$ & $3.28 \%$ & $3.44 \%$ & $29.63 \%$ \\
\hline 12 & $3.10 \%$ & $3.12 \%$ & $3.09 \%$ & $2.37 \%$ & $2.66 \%$ & $17.20 \%$ \\
\hline 13 & $4.55 \%$ & $4.55 \%$ & $4.52 \%$ & $3.98 \%$ & $4.03 \%$ & $24.36 \%$ \\
\hline 21 & $2.61 \%$ & $2.63 \%$ & $2.60 \%$ & $1.92 \%$ & $2.15 \%$ & $13.35 \%$ \\
\hline 22 & $4.12 \%$ & $4.12 \%$ & $4.09 \%$ & $3.36 \%$ & $3.65 \%$ & $20.10 \%$ \\
\hline 23 & $4.41 \%$ & $4.36 \%$ & $4.35 \%$ & $3.65 \%$ & $3.78 \%$ & $22.98 \%$ \\
\hline 24 & $3.30 \%$ & $3.29 \%$ & $3.27 \%$ & $2.42 \%$ & $2.82 \%$ & $15.14 \%$ \\
\hline 31 & $2.96 \%$ & $2.99 \%$ & $2.94 \%$ & $2.20 \%$ & $2.43 \%$ & $12.27 \%$ \\
\hline 32 & $2.97 \%$ & $2.92 \%$ & $2.91 \%$ & $1.72 \%$ & $2.59 \%$ & $7.47 \%$ \\
\hline 33 & $2.91 \%$ & $2.86 \%$ & $2.84 \%$ & $1.76 \%$ & $2.58 \%$ & $8.79 \%$ \\
\hline 34 & $3.08 \%$ & $3.05 \%$ & $3.03 \%$ & $2.04 \%$ & $2.69 \%$ & $12.95 \%$ \\
\hline 41 & $3.05 \%$ & $3.01 \%$ & $3.00 \%$ & $1.99 \%$ & $2.66 \%$ & $12.06 \%$ \\
\hline 42 & $2.99 \%$ & $2.92 \%$ & $2.92 \%$ & $1.83 \%$ & $2.53 \%$ & $10.37 \%$ \\
\hline 51 & $2.86 \%$ & $2.81 \%$ & $2.81 \%$ & $1.73 \%$ & $2.49 \%$ & $8.89 \%$ \\
\hline 52 & $3.04 \%$ & $2.99 \%$ & $2.98 \%$ & $1.84 \%$ & $2.72 \%$ & $12.15 \%$ \\
\hline 61 & $3.85 \%$ & $3.88 \%$ & $3.84 \%$ & $3.04 \%$ & $3.53 \%$ & $18.76 \%$ \\
\hline 71 & $2.36 \%$ & $2.40 \%$ & $2.35 \%$ & $1.64 \%$ & $1.92 \%$ & $9.71 \%$ \\
\hline 72 & $2.42 \%$ & $2.46 \%$ & $2.42 \%$ & $1.60 \%$ & $1.98 \%$ & $10.33 \%$ \\
\hline 73 & $3.32 \%$ & $3.33 \%$ & $3.30 \%$ & $2.39 \%$ & $2.81 \%$ & $13.46 \%$ \\
\hline 74 & $2.72 \%$ & $2.72 \%$ & $2.69 \%$ & $1.87 \%$ & $2.29 \%$ & $12.57 \%$ \\
\hline 81 & $2.56 \%$ & $2.64 \%$ & $2.55 \%$ & $1.77 \%$ & $2.08 \%$ & $11.36 \%$ \\
\hline 82 & $3.02 \%$ & $3.01 \%$ & $2.99 \%$ & $2.21 \%$ & $2.45 \%$ & $11.17 \%$ \\
\hline 83 & $3.32 \%$ & $3.36 \%$ & $3.31 \%$ & $2.73 \%$ & $2.66 \%$ & $15.00 \%$ \\
\hline 91 & $4.26 \%$ & $4.20 \%$ & $4.19 \%$ & $3.43 \%$ & $3.67 \%$ & $21.97 \%$ \\
\hline 92 & $5.05 \%$ & $5.03 \%$ & $5.02 \%$ & $4.34 \%$ & $4.74 \%$ & $27.28 \%$ \\
\hline 93 & $2.95 \%$ & $2.95 \%$ & $2.92 \%$ & $2.01 \%$ & $2.39 \%$ & $11.02 \%$ \\
\hline 100 & $3.12 \%$ & $3.11 \%$ & $3.08 \%$ & $2.21 \%$ & $2.67 \%$ & \\
\hline
\end{tabular}

Source: RDMOD, calculated by ROA

Note: 1 For high-level occupations (isco-88 codes 11-40) and army occupations, the estimated outflow is reduced by $10 \%$, for low-level occupations (isco- 88 codes $40-99$ ) the estimated outflow is reduced by $5 \%$. 
In Table 5.1 the results for Germany are reported. In the baseline scenario, RD is $3.12 \%$. Replacement demand is highest in occupations 92, 13, 23 and 91 (RD>=4.25\%).

The relation between the baseline RD and the \% elderly is clear cut. In Figure 5.1 we observe a clear positive relation between the percentage elderly (vertical $x$-as) and $\mathrm{RD}$ (horizontal x-as).

Figure 5.1 Relation RD and \% elderly in baseline scenario - Germany

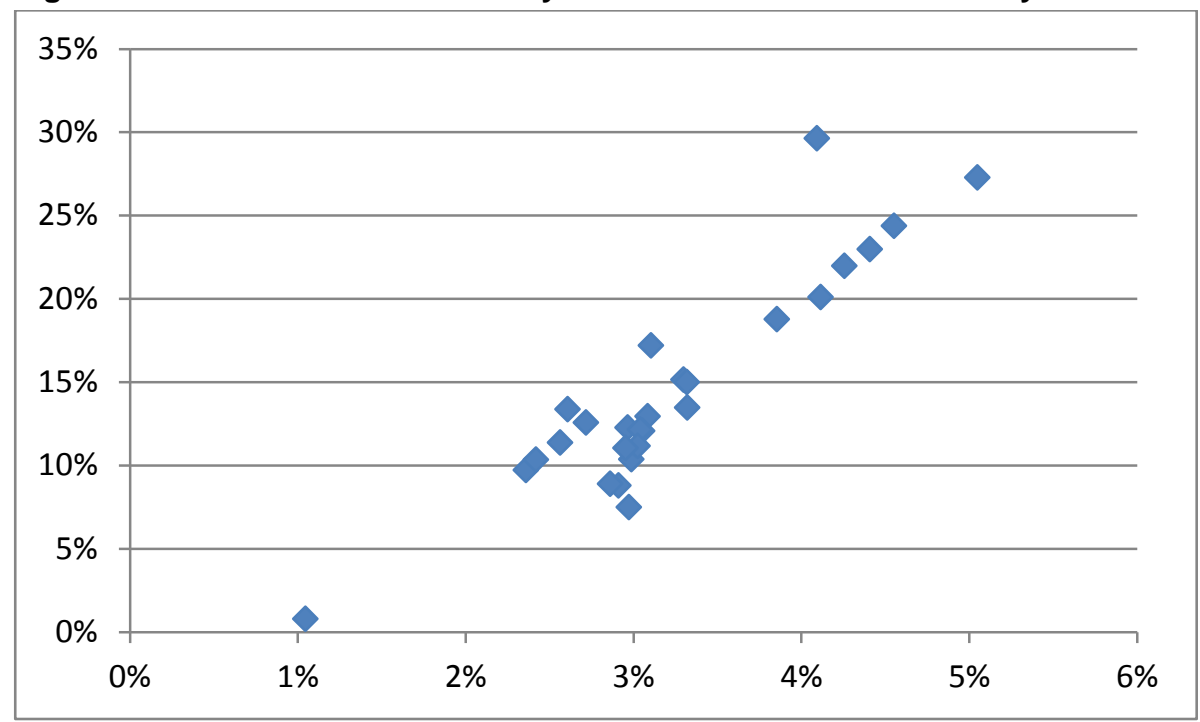

Source: RDMOD, calculated by ROA

All the different scenarios decrease the overall RD for Germany. Nevertheless, certain occupations exhibit an increase in RD in some of the alternative scenarios. This holds especially for the scenarios in which we play around with the predicted participation rates. This is not surprising as Figure 3.1 has shown that these scenarios do not always (i.e. not for all age, gender, year-combinations) increase the predicted participation rates compared to the baseline scenario. The extent to which $\mathrm{RD}$ is changed, therefore depends on the age-gender distribution of the occupations.

The other two scenarios, by construction, imply a decrease in RD for all occupations. The overall $\mathrm{RD}$ is much more affected than in the other two alternative scenarios. The scenario in which the predicted outflow is decreased (with $5 \%$ for the low-skilled occupations and with $10 \%$ for the high-skilled occupations) decreases the overall RD to $2.21 \%$. It does not come as a surprise that RD in the high-skilled occupations decreases more than in the low-skilled occupations. The scenario in which the retirement age is extended to 70, also clearly leads to a reduction in RD. On average it holds that the larger the percentage elderly, the larger the decrease in RD due to a later retirement age.

In Table 5.2 the results for Italy are reported. 
Table 5.2 Replacement demand Italy under baseline and alternative scenarios

\begin{tabular}{|c|c|c|c|c|c|c|}
\hline \multirow[t]{2}{*}{ isco } & \multirow[t]{2}{*}{ Default } & \multicolumn{2}{|c|}{ Changes in participation } & \multirow{2}{*}{$\begin{array}{l}\text { Adjusted } \\
\text { outflow }\end{array}$} & \multirow{2}{*}{$\begin{array}{l}\text { Ret age } \\
\quad 70\end{array}$} & \multirow[t]{2}{*}{$\%$ elderly } \\
\hline & & $8 \%$ up & NL & & & \\
\hline 1 & $0.94 \%$ & $0.95 \%$ & $0.92 \%$ & $0.36 \%$ & $0.78 \%$ & $2.87 \%$ \\
\hline 11 & $5.18 \%$ & $5.15 \%$ & $5.13 \%$ & $4.52 \%$ & $4.44 \%$ & $29.09 \%$ \\
\hline 12 & $4.28 \%$ & $4.27 \%$ & $4.25 \%$ & $3.63 \%$ & $3.52 \%$ & $23.44 \%$ \\
\hline 13 & $3.77 \%$ & $3.75 \%$ & $3.73 \%$ & $2.99 \%$ & $3.28 \%$ & $20.83 \%$ \\
\hline 21 & $2.49 \%$ & $2.48 \%$ & $2.46 \%$ & $1.79 \%$ & $2.11 \%$ & $11.18 \%$ \\
\hline 22 & $4.12 \%$ & $4.09 \%$ & $4.06 \%$ & $3.30 \%$ & $3.19 \%$ & $13.54 \%$ \\
\hline 23 & $4.49 \%$ & $4.43 \%$ & $4.42 \%$ & $3.45 \%$ & $3.66 \%$ & $18.65 \%$ \\
\hline 24 & $3.44 \%$ & $3.41 \%$ & $3.40 \%$ & $2.56 \%$ & $2.96 \%$ & $15.53 \%$ \\
\hline 31 & $1.95 \%$ & $1.95 \%$ & $1.93 \%$ & $1.29 \%$ & $1.49 \%$ & $7.70 \%$ \\
\hline 32 & $2.75 \%$ & $2.71 \%$ & $2.69 \%$ & $1.49 \%$ & $2.30 \%$ & $7.34 \%$ \\
\hline 33 & $3.58 \%$ & $3.51 \%$ & $3.50 \%$ & $2.22 \%$ & $2.99 \%$ & $11.50 \%$ \\
\hline 34 & $2.59 \%$ & $2.57 \%$ & $2.54 \%$ & $1.56 \%$ & $2.19 \%$ & $9.67 \%$ \\
\hline 41 & $2.56 \%$ & $2.53 \%$ & $2.50 \%$ & $1.35 \%$ & $2.12 \%$ & $6.90 \%$ \\
\hline 42 & $2.27 \%$ & $2.24 \%$ & $2.22 \%$ & $1.04 \%$ & $1.90 \%$ & $6.50 \%$ \\
\hline 51 & $2.34 \%$ & $2.32 \%$ & $2.30 \%$ & $1.15 \%$ & $2.05 \%$ & $8.57 \%$ \\
\hline 52 & $1.97 \%$ & $1.95 \%$ & $1.94 \%$ & $0.84 \%$ & $1.77 \%$ & $8.77 \%$ \\
\hline 61 & $4.32 \%$ & $4.30 \%$ & $4.29 \%$ & $3.70 \%$ & $3.75 \%$ & $26.00 \%$ \\
\hline 71 & $2.07 \%$ & $2.08 \%$ & $2.05 \%$ & $1.45 \%$ & $1.65 \%$ & $10.55 \%$ \\
\hline 72 & $1.89 \%$ & $1.90 \%$ & $1.87 \%$ & $1.32 \%$ & $1.38 \%$ & $8.37 \%$ \\
\hline 73 & $2.31 \%$ & $2.31 \%$ & $2.28 \%$ & $1.46 \%$ & $1.96 \%$ & $9.02 \%$ \\
\hline 74 & $2.84 \%$ & $2.81 \%$ & $2.80 \%$ & $1.92 \%$ & $2.39 \%$ & $11.07 \%$ \\
\hline 81 & $1.58 \%$ & $1.59 \%$ & $1.56 \%$ & $0.88 \%$ & $1.10 \%$ & $5.44 \%$ \\
\hline 82 & $1.79 \%$ & $1.78 \%$ & $1.75 \%$ & $0.78 \%$ & $1.50 \%$ & $4.87 \%$ \\
\hline 83 & $2.08 \%$ & $2.09 \%$ & $2.06 \%$ & $1.49 \%$ & $1.50 \%$ & $9.82 \%$ \\
\hline 91 & $3.30 \%$ & $3.26 \%$ & $3.24 \%$ & $2.04 \%$ & $2.81 \%$ & $13.88 \%$ \\
\hline 92 & $2.85 \%$ & $2.82 \%$ & $2.80 \%$ & $1.87 \%$ & $2.32 \%$ & $15.58 \%$ \\
\hline 93 & $1.80 \%$ & $1.80 \%$ & $1.78 \%$ & $1.04 \%$ & $1.39 \%$ & $7.52 \%$ \\
\hline 100 & $2.71 \%$ & $2.69 \%$ & $2.66 \%$ & $1.76 \%$ & $2.25 \%$ & \\
\hline
\end{tabular}

Source: RDMOD, calculated by ROA

Note: 1 For high-level occupations (isco-88 codes: 11-40) and army occupations, the estimated outflow is reduced by $10 \%$, for low-level occupations (isco- 88 codes: $40-99$ ) the estimated outflow is reduced by $5 \%$.

The baseline scenario in Italy yields a lower RD than in Germany, $2.71 \%$ of the workers in Italy need to be replaced. The scenario in which the 2010-participation rate is yearly increased by $0.8 \%$-points only implies a small decrease in the overall RD. As in the German case, not for all underlying occupations, RD decreases. 
Nevertheless, for most of the low-skilled occupations, RD does decrease slightly in this alternative scenario.

The scenario in which the changes in predicted participation rates for the Netherlands are put onto those for Italy pays off more than in the German case. This is not too surprising as for Italy, the expected participation rates under this scenario are for men clearly higher than in the baseline scenario (see Figure 3.2).

Adjusting outflow coefficients lowers RD to an unrealistic level; the overall RD is predicted to be $1.76 \%$ in this scenario. The scenario, in which the constructed retirement age is set to be 70 , decreases the overall $\mathrm{RD}$ to $2.25 \%$. Again, $\mathrm{RD}$ decreases most for occupations in which the percentage of the elderly is larger. 


\section{Discussion and conclusions}

In this report, we have played around with several model specifications of the RDMOD to see how sensitive the model is with respect to these specifications. Moreover, these exercises give us some insight in the extent to which RD may reduce if policies targeting at postponing retirement affect $R D$.

From these exercises we can conclude that changes in the predicted participation rates (for age-sex-year combinations) do not affect $\mathrm{RD}$ to a large extent for the two countries (Germany and Italy) analyzed here. This might be due to the chosen scenarios, but the overall impression is that $\mathrm{RD}$ is quite robust with respect to slight changes in the predicted participation rates.

As we have seen already in Wilson et al. (2013), the scenario in which the constructed retirement age is set to 70 (i.s.o. 67.5\%), lowers the European RD from 2.8 to $2.3 \%$. For Germany and Italy, a similar reduction is found. Replacement demand decreases most for the occupations in which most elderly are working.

Playing around with outflow coefficients affects the model to a much larger extent. The scenario in which we play around with the outflow coefficients stands for the (maybe even more realistic) case in which policy changes heterogeneously stimulate workers to stay in the labour market for a longer time. However, as playing around with outflow coefficients is somewhat counter-intuitive, new scenario analyses will be developed which take into account heterogeneous changes in future participation rates. Most likely, we will focus on heterogeneity in gender and low/high skills occupations as these groups react often differently to policy changes.

In the future, similar exercises will be performed for all countries to see how sensitive the replacement demand in all countries is with respect to several specifications. 


\section{$7 \quad$ References}

Clerx, Cörvers, Dijksman, Fouarge \& Künn-Nelen (2014) Methodiek arbeidsmarktprognoses en -indicatoren 2013-2018, ROA-TR-2014/3

De Grip, Fouarge \& Montizaan (2013) How sensitive are individual retirement expectations to raising the retirement age? De Economist, 161:225-251.

Euwals, R., van Vuuren, D. \& Wolthoff, R. (2010). Early retirement behaviour in the Netherlands: Evidence from a policy reform. De Economist, 158: 209-236.

Fouarge, D. \& A. de Grip (2014). Gaan 50-plussers meer investeren in hun scholing? Tilburg University, Netspar, NEA paper 54.

Kriechel (2011) Forecasting skill supply and demand in Europe to 2020: Replacement demand

Nelissen (2001) Het effect van wizzigingen in vervroegde uittredingsregelingen op de arbeidsparticipatie van oudere werknemers. Ministry of Social Affairs and Employment, The Hague

OECD (2014) Ageing and Employment Policies: Netherlands 2014: Working Better with Age, OECD Publishing.

Wilson, Alexandri, Bevan, Künn-Nelen, Skriabikova (2013) Mid-term skills supply and demand forecast. Methodology and Assumptions. Deliverable \#2 (in response to open invitation to tender Cedefop No:AO/RPA/AZU-VKVET/skill-forecast/003/12) 


\section{Appendix}

\subsection{Baseline scenario for Europe as a whole}

Figure 7. Annual replacement demand by country (2012-2021)

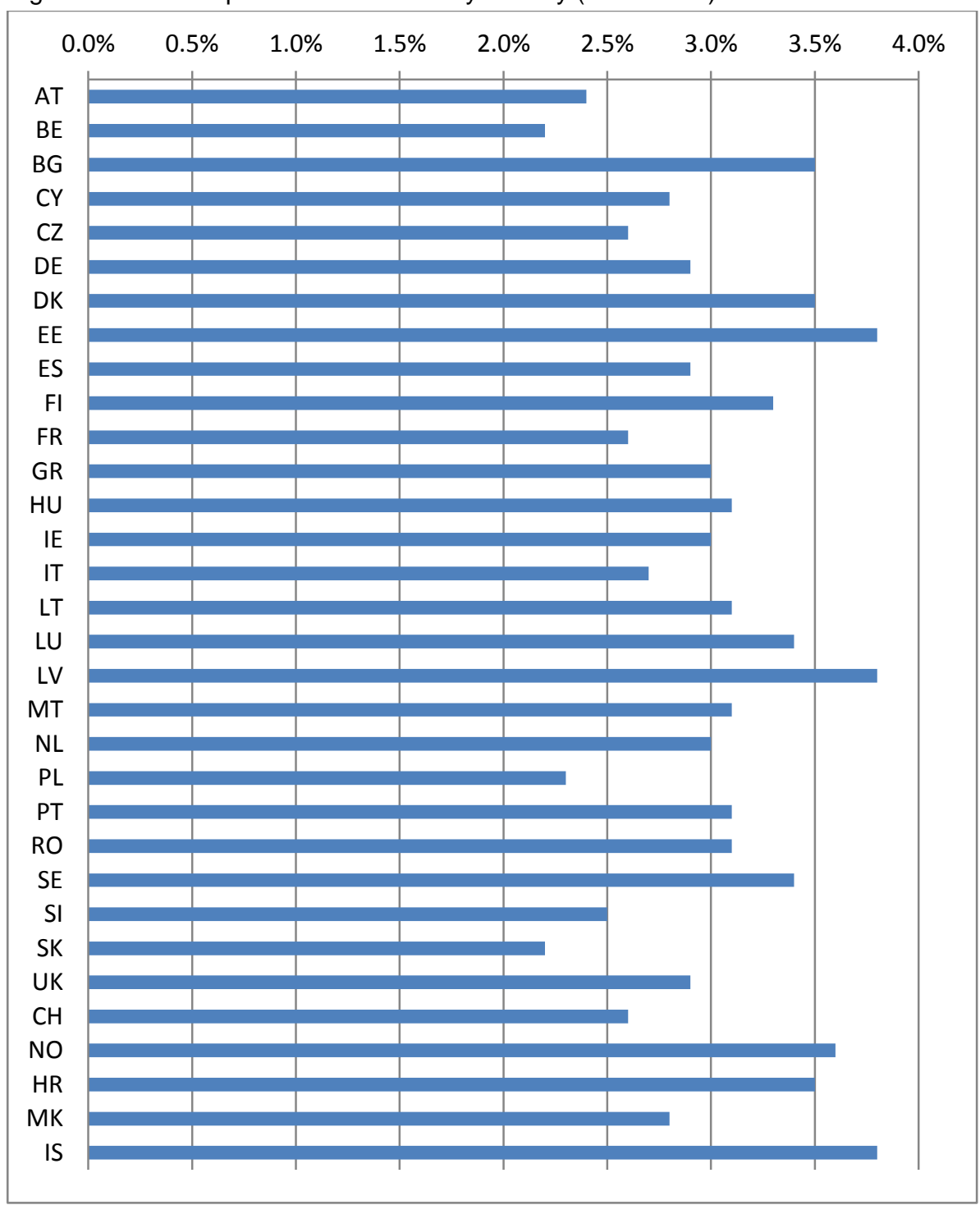

Source: RDMOD, calculated by ROA, reported in Wilson et al. (2013) 